\title{
TU/e EmonOWEN

\section{Influence of multiple air gaps on the performance of electrical machines with (semi) Halbach magnetization}

\section{Citation for published version (APA):}

Paulides, J. J. H., Gysen, B. L. J., Meessen, K. J., Tang, Y., \& Lomonova, E. (2011). Influence of multiple air gaps on the performance of electrical machines with (semi) Halbach magnetization. IEEE Transactions on Magnetics, 47(10), 2664-2667. https://doi.org/10.1109/TMAG.2011.2159368

DOI:

10.1109/TMAG.2011.2159368

Document status and date:

Published: 01/01/2011

\section{Document Version:}

Publisher's PDF, also known as Version of Record (includes final page, issue and volume numbers)

\section{Please check the document version of this publication:}

- A submitted manuscript is the version of the article upon submission and before peer-review. There can be important differences between the submitted version and the official published version of record. People interested in the research are advised to contact the author for the final version of the publication, or visit the $\mathrm{DOI}$ to the publisher's website.

- The final author version and the galley proof are versions of the publication after peer review.

- The final published version features the final layout of the paper including the volume, issue and page numbers.

Link to publication

\section{General rights}

Copyright and moral rights for the publications made accessible in the public portal are retained by the authors and/or other copyright owners and it is a condition of accessing publications that users recognise and abide by the legal requirements associated with these rights.

- Users may download and print one copy of any publication from the public portal for the purpose of private study or research.

- You may not further distribute the material or use it for any profit-making activity or commercial gain

- You may freely distribute the URL identifying the publication in the public portal.

If the publication is distributed under the terms of Article 25fa of the Dutch Copyright Act, indicated by the "Taverne" license above, please follow below link for the End User Agreement:

www.tue.nl/taverne

Take down policy

If you believe that this document breaches copyright please contact us at:

openaccess@tue.nl

providing details and we will investigate your claim. 


\title{
Influence of Multiple Air Gaps on the Performance of Electrical Machines With (Semi) Halbach Magnetization
}

\author{
Johannes J. H. Paulides, Bart L. J. Gysen, Koen J. Meessen, Yang Tang, and Elena A. Lomonova \\ Eindhoven University of Technology, Eindhoven, 5600 MB, The Netherlands
}

\begin{abstract}
The ever increasing necessity to improve torque density while simultaneously maintaining high efficiency is a constant point of concern for electrical machine designers. This is mainly driven by the need for direct-drive solutions in evermore applications. This paper presents a general mesh-free description of the magnetic field distribution in multiple air-gap electromagnetic machines, although the tool is also useful for single air-gap machines, actuators, and other magnetic devices. The used method is based on transfer relations and Fourier theory, which can provide the magnetic field solution for a wide class of 2-D boundary value problems. This technique is in this paper applied to the rotary multiple air-gap machine with slotless (without slots but with and without rotor back-iron) armature. The presented analysis is compared to finite-element analysis for the multiple-layer winding, which shows the applicability of this method for future optimization. It is shown that multiple air-gap machines make better use of the volume and for short axial lengths where a single-side bearing configuration can be utilized provides a means to improve the achievable torque density.
\end{abstract}

Index Terms-Air-gap stress, electrical machines, multi-air-gap, multiple air gap, permanent magnet, shear stress, torque density.

\section{INTRODUCTION}

$\mathbf{I}$ NCREASING the torque density of electrical machines while simultaneously maintaining high efficiency is a constant point of concern for electrical machine designers, especially since an increasing number of applications are considering direct-drive machines at relatively low angular velocities [1], [2]. This paper concerns with the influence of multiple air gaps on the total electrical machines force density using a semianalytical technique based on Fourier analysis and separation of variables.

Many interesting solutions are being sought after to improve the torque density of electrical machines. In general are electrical machines, especially in applications that demand low speeds while maintaining relatively high efficiency, coupled with a gearbox, which can be either a planetary gearbox or a more exotic magnetic gearbox. Designers have integrated two components, either with or without mutual use of material to increase the overall system torque efficiency. Obviously, integrating with mutual use of flux guiding material does minimize the required volumetric demands and ensure a high material use in electrical machines.

Alternatively, designers have sought after electrical machines with multiple air gaps to improve the torque density [3]. These machines are more complicated to construct compared to their single air-gap counterparts, since the rotor is rotating around a stationary stator which implies that quite difficult tribology is required. However, this can be solved by supporting both the rotor and stator from a single side [4]. This is also utilized in axial-field machines and when the axial length of the machine is maintained to be short this provides for a feasible solution. Further, this allows for numerous air gaps to be utilized, and therefore, this paper will present the 2-D analysis of multiple air-gap machines as opposed to single air gap, as shown in Fig. 1.

Manuscript received February 21, 2011; revised June 03, 2011; accepted June 05, 2011. Date of current version September 23, 2011. Corresponding author: J. J. H. Paulides (e-mail: j.j.h.paulides@tue.nl).

Color versions of one or more of the figures in this paper are available online at http://ieeexplore.ieee.org.

Digital Object Identifier 10.1109/TMAG.2011.2159368

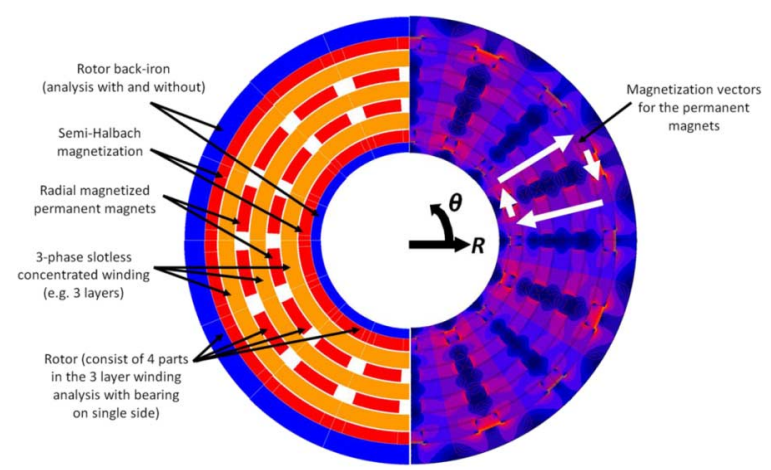

Fig. 1. Radial cross section of three-layer winding (copper color) multiple air-gap machine with equipotential contours (detailed model: Fig. 2).

\section{Multiple Air-Gap Electrical Machine}

Briefly, the multiple air-gap machine is constructed so that multiple machines are nested inside one another. The outer rotor part has semi-Halbach magnet structure (with or without backiron) at the outside surface of the outer air gap with the main flux directed inward/outward, as shown in Fig. 1. The inner rotor parts have magnets that direct the flux outward/inward; their number depends on the number of winding layers. The most inner surface of the rotor part has again a semi-Halbach magnet structure with or without back-iron. Each winding layer consists of three-phase connected concentrated coils, which could also be replaced by any other coil arrangement, e.g., distributed, torroidal [4], and wound coils. In this topology, the outer (inwards directed) magnets drive flux across the multiple air gaps to the inside surface of the rotor; the flux then travels circumferentially to the next pole, back across the multiple air gaps to the outside surface of the rotor. The torque has been calculated using the Maxwell stress tensor in the middle of each air gap (one layer winding - two air gaps, two layer winding - four air gaps, etc). The outcome of each winding layer (two air gaps) proves to be comparable to single air-gap electrical machines (slotted). Since the working surfaces of the stator (windings) are both used, in comparison with conventional machines, the structure of these multiple air-gap machines allows the exploitation of a higher 


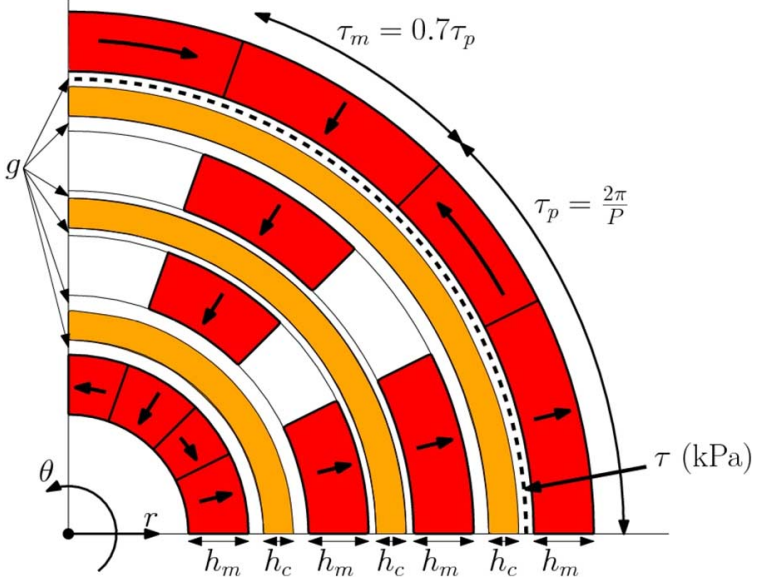

Fig. 2. Boundary value problem: A multiple air gap three winding layers (i.e., six air gaps) three-phase brushless PM machine without rotor back-iron.

percentage of the stator winding used for the production of machine torque. As such shear stress values exceeding the $47.5 \mathrm{kPa}$ (forced air cooling), in generally considered for brushless permanent magnet cored forced cooled electrical machines, can be achieved with the presented slotless multiple air-gap machine as discussed in Section VI.

\section{ANALYTICAL APPROACH}

Several analytical, semianalytical, and numerical techniques exist in the literature to model electrical machines [5]. In general, each type of problem will have its own optimal modeling technique, since ultimate accuracy is not always required and a low computational time could be more useful especially when trying to optimize electromagnetic devices. A large class of the mentioned methods, such as magnetic equivalent circuits, SchwarzChristoffel conformal mapping [6], finite-element modeling [7], and boundary element modeling [8] require geometrical discretization prior to the calculation of the electromagnetic field distribution; hence, only solutions at the predefined points can be obtained. In ironless structures, without concentrated magnetic fields, or machines with a small single or multiple air gaps and a large outer size, these methods become even more problematic due to the necessity of a high mesh density and/or size.

The analytical method used in this paper calculates the electromagnetic fields using transfer relations and Fourier analysis. The direct solution of the magnetostatic Maxwell equations is used in the polar coordinate system [6], as shown in Fig. 2. This analysis technique is utilized and extended to be able to deal with multiple air-gap electrical machines. The disadvantage of this method is that no irregular iron shapes can be considered and that the magnet should have a simple geometric shape and magnetization direction (suitable for multiple air-gap machine as shown in Fig. 1). The one to three layer winding analytical solutions are compared with 2-D finite-element analysis (Cedrat FLUX2D [7]) as shown in Section VI.

\section{MODEL FORMULATION}

To obtain a semianalytical field solution, the following assumptions have to be made:

1) the problem can be represented by a 2-D model;
2) the soft- and hard-magnetic materials are linear;

3) the soft-magnetic material (iron) is infinite permeable;

4) the materials are homogeneous;

5) the source terms are invariant within one region.

All electromagnetic devices have a 3-D geometry; however, since only 2-D problems can be considered, the geometry should be invariant with one of the three dimensions, or its dependence should be negligible. In this analysis, this is valid, since the 3-D effects due to the finite axial length are often small or negligible. It needs noting that in concentrated coil machines, the end inductance can be a significant part of the complete inductance and hence should be estimated by measurements or 3-D finite-element analysis. The analytical solution assumes linear, isotropic, and homogenous permeability of all materials. As such, permanent magnets are modeled with a linear magnetization curve in the second quadrant with a remanent flux density and a relative recoil permeability. The relative permeability of the soft-magnetic material is assumed to be infinite. This is assumption is accurate for slotless machines with or without rotor back-iron, since the flux density levels in the back-iron are kept below 1.4 T. The source regions, magnets or current carrying coils, are invariant in the normal direction described by multiple regions [9].

\section{Semianalytical Solution}

In order to solve the magnetostatic field distribution, the magnetic flux density can be written in terms of the magnetic vector potential $\vec{A}$ as

$$
\vec{B}=\nabla \times \vec{A}
$$

The definition of the magnetization vector $\vec{M}$ as employed by Zhu [14] will be used wherein

$$
\vec{M}=\chi \vec{H}+\vec{M}_{0}, \quad \text { where } \quad \vec{M}_{0}=\frac{\vec{B}_{\text {rem }}}{\mu_{0}}
$$

with $\chi$ the magnetic susceptibility and $\vec{M}_{0}$ the residual magnetization. This definition of the magnetization vector gives the constitutive relation in the form of

$$
\vec{B}=\mu_{0}(\vec{H}+\vec{M})=\mu_{0} \mu_{r} \vec{H}+\mu_{0} \vec{M}
$$

where $\mu_{r}=(1+\chi)$ is the relative permeability of the considered region. This reduces the magnetostatic Maxwell equations to a Poisson equation for every region $k$, given by

$$
\nabla^{2} \vec{A}=-\mu_{0}\left(\nabla \times \vec{M}_{0}\right)-\mu \vec{J}
$$

with $\mu=\mu_{0} \mu_{r}$ and $\vec{J}$ the current density in the considered region. A 2-D boundary value problem is considered in the polar coordinate system; hence, the magnetization vector $\vec{M}_{0}$ only has components in the radial and angular direction and the current density vector has only a component in the axial direction, $J_{z}$. Therefore, the magnetic vector potential has only a component in the axial direction which is dependent on the radial and angular direction. The Poisson equation for every region is given by

$$
\frac{1}{r} \frac{\partial}{\partial r} r \frac{\partial A_{z}}{\partial r}+\frac{1}{r^{2}} \frac{\partial^{2} A_{z}}{\partial \theta^{2}}=-\mu_{0}\left(\frac{1}{r} \frac{\partial r M_{\theta}}{\partial r}-\frac{1}{r} \frac{\partial M_{r}}{\partial \theta}\right)-\mu J_{z} \cdot
$$




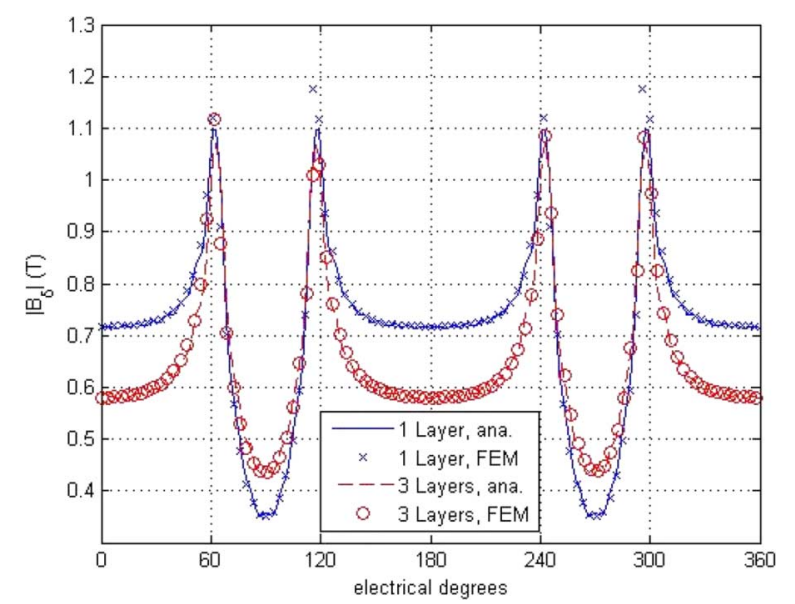

Fig. 3. Comparison of the modulus of the flux density in the outer air gap between semianalytical tool and finite-element analysis.

TABLE I

GEOMETRICAL DIMENSIONS

\begin{tabular}{|c|c|c|c|}
\hline$B_{\text {rem }}$ & $1.34 \mathrm{~T}$ & $h_{c}$ & $13 \mathrm{~mm}$ \\
\hline$D_{\text {outer,magnet }}$ & $330 \mathrm{~mm}$ & $g$ & $1.0 \mathrm{~mm}$ \\
\hline$L_{a x}$ & $100 \mathrm{~mm}$ & $J_{r m s}$ & $5 \mathrm{~A} / \mathrm{mm}^{2}$ \\
\hline$\mu_{r}$ & 1.06 & $h_{m}$ & $10 \mathrm{~mm}$ \\
\hline
\end{tabular}

The magnetic flux density distribution can be obtained from the solution of the magnetic vector potential by means of (1), and the magnetic field strength is obtained from the flux density distribution by means of the constitutive relation (3). Following, between every region, the normal flux density and angular magnetic field strength are set continuous. This leads to a set of equations in terms of the unknown coefficients of the field solution which are solved by matrix inversion. Consequently, the torques are calculated using Maxwell stress for the various air gaps.

In order to validate the analytical modeling, the flux density waveforms in the outer air gap are compared between the analytical and finite-element analysis for both the single and triple layer winding (see Fig. 3) with the dimensions as summarized in Table I. This shows that a good agreement is apparent between the analytical model and finite-element analysis.

\section{AIR-GAP SHEAR STRESS}

For fixed speed and load applications, the merits of competing machine technologies can be reasonably quantified and compared, thereby facilitating a well-informed selection of the most appropriate machine technology. However, for variable-speed, variable duty cycle applications, for which the machine operational specification may not be as tightly defined, the selection of the most appropriate machine technology may seem to be more arbitrary, or even may be influenced by personal/industry preference. Nevertheless, an informed choice needs to be made and justified. For fixed rotor geometry, the relative merits of competing brushless PM machine, either ac or dc, technologies can be assessed from their respective output coefficient, typical examples of which are presented in Table II for forced-air ventilated machines, as reported by West [10]. While the values pre-
TABLE II

AIR-GAP SHEAR STRESS FOR VARIOUS ELECTRICAL MACHINES [10]

\begin{tabular}{|c|c|}
\hline & Shear stress $\sigma(\mathrm{kPa})$ \\
\hline Brushed DC & 16.0 \\
\hline Induction machine & 14.7 \\
\hline Inverter-fed Induction machine & 18.4 \\
\hline Brushless AC & $\sim 47.5^{*}$ \\
\hline Brushless DC & 42.3 \\
\hline Switched reluctance (high ripple) & 19.4 \\
\hline
\end{tabular}

* Estimated using authors design experience.

sented in Table II are indicative of machine designs for both industrial and prototype variable-speed drives, they facilitate a reasonable comparison of competing machine technologies for electric vehicle traction drives and give some insight into the design constraints of each technology.

In machine design, magnetic and electric loadings are inextricably linked, e.g., while the maximum permissible flux density in the iron core of a machine has increased only slightly over the last 50 years, the tolerable electrical loading has effectively doubled over that period. This is mainly due to the change from organic insulating materials, which were suitable for maximum winding operating temperatures of only around $105^{\circ}$, to higher temperature synthetic insulation materials now capable of continuous operation of up to $220^{\circ}$. This has permitted either an increase in electric loading or a reduction in the coil size providing a larger air gap diameter. However, current technology is only progressing at a relatively slow rate; therefore, machine designers are investigation how to improve the torque density with, for example, multiple air-gap machines.

\section{Multiple AIR-Gap Machine ANALYsis}

The multiple winding layer radial-flux machine can possess a variety of topologies based on different structure of windings, slots, and magnet arrangements. If in-line magnetized magnets are used, the machines can be designated as shown in Fig. 2, in which Halbach-North-North-Halbach $(\mathrm{H}-\mathrm{N}-\mathrm{N}-\mathrm{H})$ type magnet polarity arrangement is used. If both the inside, inner, and outer magnets are polarized in the same direction, the magnet flux will travel radially directly from inner rotor to outer or the reverse. For this case, as shown in Fig. 1, there is only little flux traveling along the circumference of the stator core. The stator core could also be slotted and the magnets do not have to be surface mounted. As an electrical machine, multiple air-gap machines have some specific features caused by their unique mechanical configuration: rotor-armature-rotor-armature-rotor-armature-rotor (for the three winding layer motor) structure and six air gaps. Since the output torque is proportional to the air-gap surface area for the constant electrical and magnetic loadings, the first most straight forward observation coming from the increasing number of air gaps is that the torque density will be substantially boosted. This implies that for the same surface force density caused by the same surface current and air-gap flux density, the torque produced in various air gaps is larger than that of the conventional PM machine. For the topologies with concentrated windings, the torque producing winding surfaces are mostly used, since the end winding is short. This results in an improved machine efficiency. 


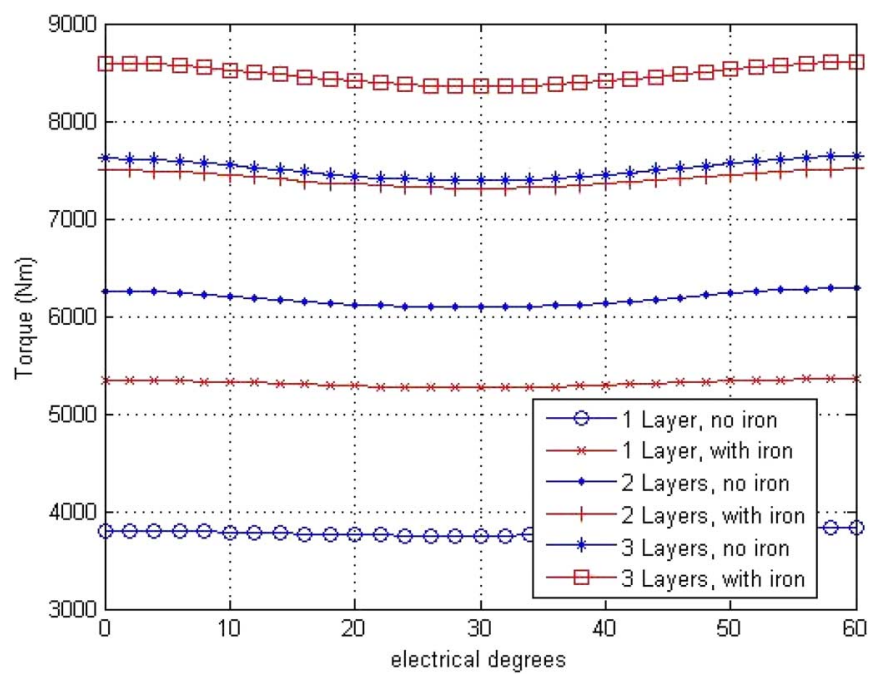

Fig. 4. Torque output for various numbers of layers, without and with back-iron.

TABLE III

Average TORQUE ON THE ROTOR

\begin{tabular}{|c|c|c|c|}
\hline & 1 layer & 2 layer & 3 layers \\
\hline No back-iron & $379 \mathrm{Nm}$ & $618 \mathrm{Nm}$ & $752 \mathrm{Nm}$ \\
\hline With back-iron & $531 \mathrm{Nm}$ & $741 \mathrm{Nm}$ & $848 \mathrm{Nm}$ \\
\hline
\end{tabular}

In total, six models have been investigated with one, two, or three winding layers. The dimensions are fixed to provide the first-order air-gap shear stress analysis, although design experience has been incorporated by chosen a suitable Halbach array ratio. The various dimensions are summarized in Table I. Fig. 4 shows the torque versus electrical angle of the rotor, where clearly an increase in total torque on the rotor is visible.

As a reference, the shear stress is taken in the middle of the outer air gap, where the single layer with back-iron constitutes to $35 \mathrm{kPa}$ instead of $47.5 \mathrm{kPa}$ as estimated for the brushless ac machine with an rms current density of $5 \mathrm{~A} / \mathrm{mm}^{2}$. However, for the double and triple layers, this has increased to 49.4 and 56.5 $\mathrm{kPa}$, respectively. The corresponding various average torques on the rotor are summarized in Table III for the dimensions and material characteristics as summarized in Table I.

It is well known that, as the machine temperature increases, the copper resistance as well as the copper losses increases, while the magnet residual flux density and the output torque decrease. Therefore, a further thermal analysis is essential to illustrate how the heat due to the copper losses inside multiple air-gap machines can be most effectively removed. This is essential, since fixing the current density does increase the overall winding copper losses. However, in this type of moving coil machines, most heat is transferred through the air gap; hence, more air gaps result in more capacity to remove the heat from the machine. One could calculate the temperature rise by considering a fixed convection coefficient along the winding surface. However, the various surface speeds of the air gaps are different, and therefore, a more complex thermal model is necessary to estimate the various temperatures. In addition, the connection portion between inner and outer rotors can be well designed as a cooling fan to provide the even better cooling condition to further improve the current density and torque density. Therefore, a thermal analysis is considered to be a subject for future research.

\section{CONCLUSION}

In summary, the multiple air-gap machine works like multiple conventional machines in series. For one winding layer, one torque producing air gap is inside and the other is outside the winding layer. This is further extended with multiple winding layers. In a single layer, both air gaps experience the same armature current. Their back EMFs are in series and may vary, depending on the air-gap flux densities. The outer and inner rotor parts are connected together by one end disc, which can also work as a cooling fan. An analytical tool was developed and verified with finite-element analysis. The results have shown that the equivalent shear stress calculated in the outer air gap has increased compared to the brushless ac machine as mentioned in Table II, $56.5 \mathrm{kPa}$ instead of $47.5 \mathrm{kPa}$. In this, the outer air-gap surface area has been taken as reference, where the average shear stress could also be taken which would be higher than the presented $16 \%$. Therefore, although this machine is not fully optimized, this paper has illustrated the potential of multiple air-gap machines and future research will be dedicated to the magnetic and thermal optimization of these machines, which finally will be validated by measurements.

\section{REFERENCES}

[1] I. Boldea, M. Topor, F. Marignetti, S. I. Deaconu, and L. N. Tutelea, "A novel, single stator dual PM rotor, synchronous machine: Topology, circuit model, controlled dynamics simulation and 3D FEM analysis of torque production," in Proc. 12th Int. Conf. Optim. Electr. Electron. Equipment, 2010, pp. 343-351.

[2] Q. F. Lu, C. Z. Fan, Y. Y. Ye, and Z. Q. Zhu, "A high torque density permanent magnet motor for oil pumping unit," J. Appl. Phys., vol. 103, no. 7, pp. 1-3, 2008.

[3] F. Messine and B. Nogarede, "Optimal design of multi-airgap electrical machines: An unknown size mixed-constrained global optimization formulation," IEEE Trans. Magn., vol. 42, no. 12, pp. 3847-3853, Dec. 2006.

[4] R. Qu and T. A. Lipo, "Dual-rotor, radial-flux, toroidally wound, permanent-magnet machines," IEEE Trans. Ind. Appl., vol. 39, no. 6, pp. 1665-1673, Nov./Dec. 2003.

[5] B. L. J. Gysen, K. J. Meessen, J. J. H. Paulides, and E. A. Lomonova, "General formulation of the electromagnetic field distribution in machines and devices using Fourier analysis," IEEE Trans. Magn., vol. 46, no. 1, pp. 39-52, Jan. 2010.

[6] D. C. J. Krop, E. A. Lomonova, and A. J. A. Vandenput, "Application of Schwarz-Christoffel mapping to permanent-magnet linear motor analysis," IEEE Trans. Magn., vol. 44, no. 3, pp. 352-359, Mar. 2008.

[7] “FLUX2D 10.2 User's Guide,” Cedrat, Meylan, France, 2008.

[8] L. C. Wrobel and M. H. Aliabadi, The Boundary Element Method. New York: Wiley, 2002.

[9] K. J. Meessen, B. L. J. Gysen, J. J. H. Paulides, and E. A. Lomonova, "Halbach permanent magnet shape selection for slotless tubular actuators," IEEE Trans. Magn., vol. 44, no. 11, pp. 4305-4308, Nov. 2008.

[10] J. G. W. West, "DC, induction, reluctance and PM motors for electric vehicles," in Proc. IEE Colloq. Motors Drives Battery Powered Propulsion, 1993, pp. 1/1-1/11. 